\title{
Determination of sex on basis of index and ring finger ratio
}

\author{
Radha $\mathrm{K}^{1^{*}}$, Kamalakkannan $\mathrm{V}^{2}$
}

${ }^{1}$ Associate Professor, 2Senior Resident, Department of Anatomy, Vinayaka M issions M edical College, Vinayaka M issions Research Foundation (Deemed To Be University), Karaikal-609609, Pondicherry, INDIA.

Email: ajjuradha@gmail.com

Abstract Background: Sex determination in identification of human remains is one of the most important components in forensic identification and it is a major task in medicolegal investigation. Aim Determination of sex using ring and index finger length and their ratios among adult population. Subjects and methods Present study was carried out on 100 indivuals of both sexes. Length of index and ring fingers and the ratios between them were estimated. Results: In females, average right 2DL varied from $57.2 \mathrm{~mm}$ to $82.65 \mathrm{~mm}$ (mean 67.26 and SD 4.644) and average right 4DL varied from 59.13mm to $79.29 \mathrm{~mm}$ (mean 67.32 and SD 4.166). Average left 2DL varied from $58.14 \mathrm{~mm}$ to $77.7 \mathrm{~mm}$ (mean 67.42 and SD 4.45 ) and average left 4DL varied from $59.29 \mathrm{~mm}$ to $79.24 \mathrm{~mm}$ (mean 66.69 and SD 4.6). Difference between mean 4DL and 2DL was 0.06 for the right hand and 0.73 for left hand. The significance difference between 2DL and 4DL among sexes is highly significant. In males, average right 2DL varied from $62.8 \mathrm{~mm}$ to $88.61 \mathrm{~mm}$ (mean 73.42 and SD 4.88 ) and average right 4DL varied from $63.34 \mathrm{~mm}$ to $88.61 \mathrm{~mm}$ (mean 73.94 and SD 4.90). Average left 2DL varied from $65.34 \mathrm{~mm}$ to $90.17 \mathrm{~mm}$ (mean 73.93 and SD 4.78). Average left 4DL varied from $63.32 \mathrm{~mm}$ to $85.10 \mathrm{~mm}$ (mean 73.98 and SD 5.01). Difference between mean 4DL and 2DL was 0.52 for right hand and 0.05 for left hand. Difference between mean 4DL and 2DL among sexes is highly significant $(p<0.001)$ Male shows statistically higher values than females for mean 2DL and 4DL in both right and left hands. Conclusion By using the anthropometric measurements of fingers, sex can be estimated with a high accuracy. It is, therefore, an important tool to be included in forensic identification when a hand is detected at the criminal scene and accidents.

Key Word: Human identification, Forensic science, Sex determination, Index/ring finger.

*Address for Correspondence:

Dr. Radha K, Associate Professor, Department of Anatomy, Vinayaka Missions Medical College, Vinayaka Missions Research Foundation (Deemed To Be University), Karaikal-609609, Pondicherry, INDIA.

Email: ajjuradha@gmail.com

Received Date: 10/09/2018 Revised Date: 13/10/2018 Accepted Date: 25/11/2018

DOI: $\mathrm{https}: / /$ doi.org/10.26611/1001831

\begin{tabular}{|c|l|}
\hline \multicolumn{2}{|c|}{ Access this article online } \\
\cline { 1 - 2 } Quick Response Code: & Website: \\
\cline { 1 - 1 } & www.medpulse.in \\
\hline
\end{tabular}

\section{INTRODUCTION}

Forensic anthropology involves identification of human remains for medico-legal purpose ${ }^{1}$. Evidence of use of anthropometry in the field of legal medicine is available since $19^{\text {th }}$ century ${ }^{2}$.Various research has estimated stature of a person by various method, formula and regression equation. ${ }^{3}$ Identification of deceased person is a major concern for forensic investigation and other law enforcement agencies. Estimation of sex is mandatory in medico-legal investigations when identification of unknown mutilated and dismembered remains are available ${ }^{4}$. Determination of sex is the authenticated parameter in identification of individual..$^{5}$ Apart from length of index and ring finger, their ratio plays a vital role in predicting sex of an individual. Index and Ring finger ratio is identified as a sexually dimorphic biometric population marker ${ }^{6}$. It is related to prenatal estrogen, testosterone and genetically controlled by HOX gene ${ }^{7}$.

\section{MATERIAL AND METHODS}

Present study was undertaken in Vinayaka Mission's Medicl College and Hospital, Karaikal involving 100 participants of age 18-23yrs and of both sexes. Informed 
consent was taken from the participants after explaining the procedure clearly. The following measurements were taken using Vernier digital Caliper. Length of index finger (2D) of both right and left hands Length of ring finger (4D) of both right and left hands Measurements were tabulated, ratio calculated and statistical analysis were done.

\section{OBSERVATION AND RESULTS}

Table 1

\begin{tabular}{|c|c|c|c|c|c|c|c|c|c|c|c|c|c|c|}
\hline \multirow{4}{*}{ Variable } & \multirow{2}{*}{\multicolumn{4}{|c|}{ Female $(n=50)$}} & \multirow{2}{*}{\multicolumn{4}{|c|}{ Male $(n=50)$}} & \multirow{2}{*}{\multicolumn{2}{|c|}{$\begin{array}{l}\text { 2D:4D ratio } \\
\text { Female }\end{array}$}} & \multirow{2}{*}{\multicolumn{2}{|c|}{ 2D:4D ratio male }} & \multirow{4}{*}{$\begin{array}{c}\text { Mean } \\
\text { 2D:4D } \\
\text { Female }\end{array}$} & \multirow{4}{*}{$\begin{array}{c}\text { Mean 2D:4D } \\
\text { Male }\end{array}$} \\
\hline & & & & & & & & & & & & & & \\
\hline & \multicolumn{2}{|c|}{ Right hand } & \multicolumn{2}{|c|}{ Left hand } & \multicolumn{2}{|c|}{ Right hand } & \multicolumn{2}{|c|}{ Left hand } & \multirow{2}{*}{ Right } & \multirow{2}{*}{ Left } & \multirow{2}{*}{ Right } & \multirow{2}{*}{ Left } & & \\
\hline & $2 \mathrm{DL}$ & $4 \mathrm{DL}$ & $2 \mathrm{DL}$ & $4 \mathrm{DL}$ & $2 \mathrm{DL}$ & $4 \mathrm{DL}$ & $2 \mathrm{DL}$ & $4 \mathrm{DL}$ & & & & & & \\
\hline Min & 57.20 & 59.13 & 58.14 & 59.29 & 62.80 & 63.34 & 65.34 & 63.32 & 0.97 & 0.93 & 0.92 & 0.944 & 0.62 & 1.39 \\
\hline Max & 82.65 & 79.29 & 77.7 & 79.24 & 88.61 & 88.61 & 90.17 & 85.10 & 1.06 & 1.07 & 1.05 & 1.061 & 1.59 & 1.59 \\
\hline Mean & 67.26 & 67.32 & 67.42 & 66.69 & 73.42 & 73.94 & 73.93 & 73.98 & 0.98 & 1.01 & 0.99 & 1.000 & 1.48 & 1.49 \\
\hline S.D & 4.644 & 4.166 & 4.45 & 4.6 & 4.88 & 4.90 & 4.78 & 5.01 & 0.13 & 0.032 & 0.04 & 0.033 & 0.13 & 0.04 \\
\hline S.E & 0.656 & 0.589 & 0.630 & 0.651 & 0.69 & 0.69 & 0.67 & 0.68 & 0.02 & 0.004 & 0.005 & 0.005 & 0.018 & 0.006 \\
\hline
\end{tabular}

In table 1,2D:4D digit ratio to be predictive of sexual dimorphism. Descriptive statistics for entire sample was computed for both right and left hand. In females, average right 2DL varied from 57.2mm to 82.65mm (mean 67.26 and SD 4.644) and average right 4DL varied from $59.13 \mathrm{~mm}$ to $79.29 \mathrm{~mm}$ (mean 67.32 and SD 4.166). Average left $2 \mathrm{DL}$ varied from $58.14 \mathrm{~mm}$ to $77.7 \mathrm{~mm}$ (mean 67.42 and SD 4.45) and average left 4DL varied from 59.29mm to 79.24mm (mean 66.69 and SD 4.6). Difference between mean 4DL and 2DL was 0.06 for the right hand and 0.73 for left hand. The significance difference between 2DL and 4DL among sexes is highly significant. In males, average right 2DL varied from 62.8mm to $88.61 \mathrm{~mm}$ (mean 73.42 and SD 4.88) and average right 4DL varied from $63.34 \mathrm{~mm}$ to $88.61 \mathrm{~mm}(\mathrm{mean} 73.94$ and SD 4.90). Average left 2DL varied from $65.34 \mathrm{~mm}$ to $90.17 \mathrm{~mm}$ (mean 73.93 and SD 4.78). Average left 4DL varied from $63.32 \mathrm{~mm}$ to $85.10 \mathrm{~mm}$ (mean 73.98 and SD 5.01). Difference between mean 4DL and 2DL was 0.52 for right hand and 0.05 for left hand. Difference between mean 4DL and 2DL among sexes is highly significant $(\mathrm{p}<0.001)$ Male shows statistically higher values than females for mean 2DL and 4DL in both right and left hands. This means males have longer index and ring fingers than females whereas 2D:4D ratio is lower for males than females.

\begin{tabular}{cccc}
\multicolumn{4}{c}{ Table 2 } \\
\hline Parameter & Female $(n=50)$ & Male $(n=50)$ & P-value \\
\hline 2D Right & $67.26 \pm 4.64$ & $73 \pm 4.88$ & 0.000 \\
2D Left & $67.42 \pm 4.45$ & $73.93 \pm 4.78$ & 0.000 \\
4D Right & $67.32 \pm 4.45$ & $73.94 \pm 4.90$ & 0.000 \\
4D Left & $66.69 \pm 4.60$ & $73.93 \pm 5.01$ & 0.000 \\
2D:4D ratio Right & $0.98 \pm 0.131$ & $0.99 \pm 0.03$ & 0.520 \\
2D:4D ratio Left & $1.01 \pm 0.032$ & $1.00 \pm 0.033$ & 0.087 \\
M ean2D:4D & $1.48 \pm 0.13$ & $1.49 \pm 0.04$ & 0.733 \\
\hline
\end{tabular}

Table 2 shows mean value of lengths of 2D, 4D and 2D: 4D in right and left hands in males and females obtained by measuring dermatoglyphics length using digital vernier caliper. From the table it is clear that 4DL is longer than $2 \mathrm{DL}$ in right and left hands in both males and females. The sex difference is for 2DL right and 2DL left then 4DL right and 4DL left were statistically significant $(\mathrm{p}<0.01)$. Then rest of other parameters 2D: 4D ratio of right and left and mean 2D:4D do not rejected.

Table 3

\begin{tabular}{ccccccc}
\hline \multirow{2}{*}{ Statistics } & \multicolumn{2}{c}{ 2D:4D ratio right hand } & \multicolumn{2}{c}{ 2D:4D ratio left hand } & \multicolumn{2}{c}{ Mean2D:4D ratio } \\
& Female & Male & Female & Male & Female & Male \\
\hline Mean & 0.9813 & 73.42 & 1.01 & 1.00 & 1.48 & 1.49 \\
S.D & 0.1310 & 4.88928 & 0.03 & 0.033 & 0.13 & 0.04 \\
95\% confidence interval & $0.944 \pm 1.018$ & $0.983 \pm 1.003$ & $1.00 \pm 1.02$ & $0.99 \pm 1.00$ & $1.44 \pm 1.52$ & $1.48 \pm 1.50$ \\
P value & 0.520 & & 0.087 & & 0.733 & \\
t value & 0.646 & & 1.729 & & 0.342 & \\
F value & 0.417 & & 2.989 & & 0.117 \\
\hline
\end{tabular}

Table 3 shows that comparison of mean of 2D:4D ratio in right and left hands of both males and females. So one of the most popular tool we used is student t test and analysis of variants. $\mathrm{P}$ value and t value were calculated and are highly 
non significant in terms of sexual differences. Our study confirms the servations of other researchers that the sex difference in index and ring finger length can be a useful sex indicator especially when DNA analysis cannot be performed. In this study, males show higher mean values in each anthropometric dimension than females.

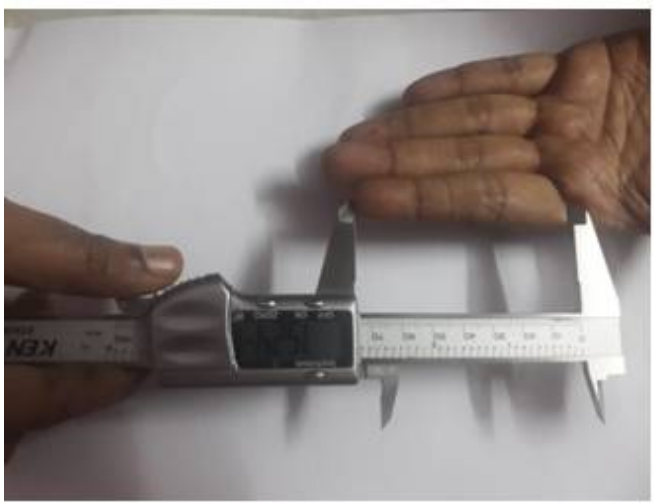

Figure 1 : Showing M easurement Of Length Of Index Finge

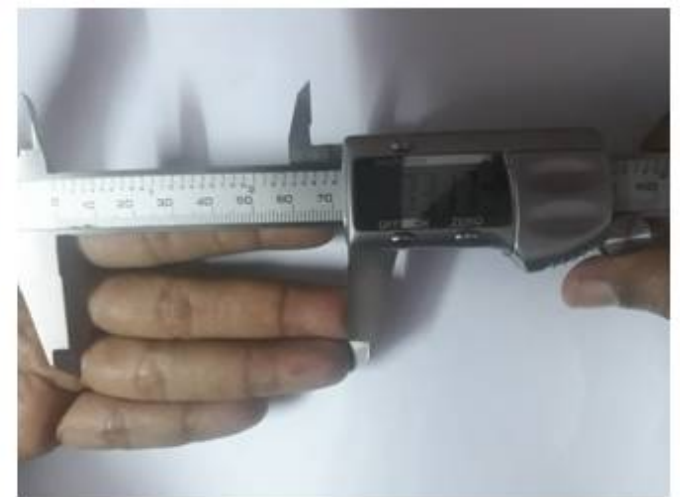

Figure 2 : Showing M easurement Of Length Of Ring Finger

\section{DISCUSSION}

Identification of human remains is the main element in any medico-legal investigation ${ }^{8}$. Even though DNA technology has simplified the process, anthropometry plays a vital role in developing countries like India because of the unavailability of man power, time and financial issues ${ }^{8}$. Frederic Wood Jones in 1920 introduced concept of DIGITAL FORMULA and he discovered that absolute length of index finger is longer than ring finger (2D>4D). ${ }^{4}$. In present study male and female don't depict the typical human digital formula whereas shows resemblance with Simian Digital Formula (2D <4D) for both sex. ${ }^{9}$ Manning et al demonstrated 2D:4D ratio is only trait that measurably explain sexual dimorphism. It reflects prenatal androgen action that high testosterone associated with low 2D:4D ratio. ${ }^{10}$ In our study finger dimensions were found to be longer in males than in females. And also we observed that the ratio 2D:4D there is only slight difference between male and females in both right and left hands. So ratio cannot be taken as a significant element for sexual dimorphism.

\section{CONCLUSION}

Therefore length of the index and ring fingers are better indicators of sexual dimorphism than the ratio 2D:4D. 2D:4D length ratio in males is greater than in females which is statistically significant. The ring finger length is greater than index finger length in both the hands of males and females. The length of index and ring fingers is more significant in assessing the sex of the individual than the ratio of $2 \mathrm{D}: 4 \mathrm{D}$.

\section{REFERENCES}

1. Jaydip Sen et al ,Estimation Of Sex From Index And Ring Finger Lengths In An Indigenous Population Of Eastern India , Journal of clinical and diagnostic research,2015Nov,Vol-9(11)wag;HC01:HC05

2. Sumita Shukla et al, The Morphometric Study of Sexual Dimorphism in Index and Ring Finger Length Ratio in Indian Population, Annals of International Medical and Dental Research, Vol(2), Issue(4)

3. Waghmare VKR et al, Estimation of the stature from the anthropometric measurement of hand length. The internet journal of biological anthropology, 2011;4(2):21-9

4. Mudasir Ahmad Khan el al, Digit ratio (2D:4D) - An Anthropometric Marker for Sexual Dimorphism in JandK population, JMSCR Volume 05 Issue 07 July 2017

5. Kanchan T, Kumar GP, Menezes RG. Index and Ring Finger ratio: a new sex determinant in the south-Indian population. Forensic Sci Int 2008; 181(1), 53-el.

6. McIntyre MH, Cohn BA, Ellison PT . Sex Dimorphism in Digital Formulae of children. Am J PhysAnthropol. 2006; 129:143-50.

7. Kyriakidis I, Papaioannidou P. Epidemiologic Study of the Sexually Dimorphic second to fourth digit ratio (2D:4D) and other finger ratios in Greek population. Coll Anthropol. 2008;32:1093-98

8. Khaled E. Aboul-Hagag et al, Determination of sex from hand dimension and Index/ring finger length ratio in Upper Egyptians, Production and hosting by Elsevier.

9. Wood- Jones F. The Principles of Anatomy as seen in the hand. London: J. and A. Churchill; 1920. p. 354.

10. Manning JT et al, The ratio of $2^{\text {nd }}$ to $4^{\text {th }}$ digit length: a predictor of sperm numbers and concentrations of testosterone, luteinizing hormone and oesterogen. Hum Reprod 1998; 13:3000e4.

\section{Source of Support: None Declared Conflict of Interest: None Declared}

